\title{
Growth in British agriculture: 1945 to present day
}

\section{By A. Winegarten, The National Farmers Union, Knightsbridge, London $S W_{\mathrm{I} X}{ }_{7} \mathrm{NJ}$}

Looking at the agricultural industry over the last 30 years one is immediately struck by three trends: the decline in the numbers of those engaged in the industry, the enlargement and increasing specialization of the average farm and the sustained growth in the volume of output over the period. Detailed statistics are not available for the whole post-war period but those that are available show that between 1946 and 1976 the numbers of full-time farmworkers fell by approximately two-thirds from 695000 to 213000 . While not fully comparable the statistics suggest that the total number of holdings declined by about $40 \%$ to 270000 and the unweighted average size of all farms rose $59 \%$ to 70 hectares. Over the period definitions have changed but it appears that in England and Wales the numbers of full-time farmers fell by almost 40\% from 215000 to 135000 and the average size of full-time holdings (crops and grass) rose $75 \%$ from 40 hectares to about 70 hectares.

On the output side the last 30 years have witnessed a doubling of the volume of agricultural output and a reduction in the average farm's mix of products. What is particularly remarkable is that this increased output has been accompanied by a consistently good quality and a continuance of the rich diversity of British agriculture comprising some fifteen major crops and products.

The purpose of this paper is to look briefly at some of the structural changes underlying this apparent paradox and to suggest how each has contributed to the industry's growth performance. Population, the main element of food demand prewar, continued to rise, but of more importance for the post-war period has been the secular decline in the magnitude of the food traded on the world market (in particular beef) together with the high level of employment and rising real income per head in the UK. This buoyant demand necessitated both an increase in production and foods of a uniform and high quality, but most importantly it had the advantage of providing a secure and stable market in which farmers could specialize and plan more easily for future production.

However, although an important factor, the level of demand does not explain the decline in the labour force or the increase in the ratio, output:input. To find an explanation we must look in more detail at the changes in the production and distribution of food. In particular I am going to consider government financial support and guarantees, the application of science to food production which manifests itself in new techniques and improved inputs, the increased use of capital, particularly machinery, and the development of marketing techniques. 


\section{Price support}

Basically the period can be viewed as one of steady diminution in the risks traditionally faced by farmers. Although some arrangements for price support were adopted in the 1930s it was not until the 1947 Agricultural Act that the system was placed on a permanent basis. The existence of firm support prices has greatly facilitated the post-war trends in British agriculture - concentration, specialization and mechanization - by reducing the risk attached to agricultural investment. The organizational improvements implemented since the war rested in part on expectations of future agricultural prosperity, and the greater security which price support systems provide to farmers has been a major cause in creating confidence. This enabled individual farmers to reduce the number of enterprises on the farm without increasing the risk of a loss in the market. Thus, each could concentrate on fewer enterprises, depending only on environment and particular skills and thereby increase output and efficiency by exploiting economies of scale.

However, I do not want to create the impression that farming is now a risk-free occupation. For example, in the last few years sharp unexpected rises in cereal prices have, at least for a time, plunged certain of the livestock sectors into serious financial difficulties. It remains to be seen to what extent the changes associated with the EEC Common Agricultural Policy will influence these post-war trends.

\section{New techniques and inputs}

Over the last 30 years the agricultural industry has undergone a technical revolution. Scientists, engineers, plant and animal breeders sustained by the universities and research stations have bombarded the industry with new products and techniques. It is to the credit of the industry that farmers have been prepared to experiment with and adopt these new methods.

It is this partnership between farming and science that has contributed most to the industry's growth performance since the war and earned British agriculture the reputation for being amongst the most efficient in the world with a level of output in relation to its manpower which is without parallel. In particular, the science of genetics has, in the space of less than 30 years, revolutionized or replaced many of the traditional crop varieties and animal breeds common before the war.

It is not my intention to go into details but one or two figures will give the order of magnitude. In 1946 the average yield per hectare for wheat and potatoes was $2.4 \mathrm{I}$ and 17.8 tonnes respectively. By 1974 these yields had risen steadily to 4.97 and 31.6 tonnes (the drought necessarily reduced yields in 1975 and 1976). Similarly the average gross yield of milk per dairy cow has risen from 2296 litres per year to 4304 litres over the same period.

Of course this increased utilization of agricultural inputs must be seen against the background of government supports and some of the credit must go to the increased use of capital and marketing techniques; but, I think there is little doubt that the technological advances employed in modern farming are the main cause of the sustained increase in the ratio, output:input over the period. 


\section{Investment}

Another feature of the structural change over the post-war period is the increased capitalization of agricultural production. Whether this is in response to, or the cause of the decline in the labour force need not be a subject for debate here. In view of the fall in agriculture's labour force since the war, large increases in gross capital formation in plant, machinery and vehicles might have been anticipated, but after allowing for inflation gross capital formation did not increase significantly until the end of the r 950 .

The explanation for this lies in the greater utilization of the existing capital stock and the extent to which new investment embodied the results of up-to-date technical advance. The stock of capital in the form of plant, machinery, vehicles, buildings and works has accumulated through successive investments by the industry. Contrary to popular conception of a labour-intensive industry, over the post-war period agriculture has become capital intensive.

Except where large areas of intensive crops are grown or very large numbers of livestock are kept there is usually at least one tractor per worker today, whereas in 1946 the ratio was one to five. But it is the introduction of technically sophisticated machines such as combine harvesters and pick-up balers, virtually unknown in 1946, that have yielded significant economies of scale. Before the war much of Lincolnshire and East Anglia were agricultural semi-wastelands offering bare subsistence to farmers and farmworkers, but they have now become highly productive partly as a result of mechanized farming. Thus, if account is taken of the improved quality of the new capital investment the resulting substantial economies of scale can go some way towards an understanding of the phenomenal rise in the ratio, output:labour over the period. Indeed, the emergence in the south and east of large arable farms operated with large and complex machines is a visual sign of this profound structural change.

\section{Marketing}

In the post-war period the traditional links among the institutions comprising the agricultural marketing chain have in a number of cases been radically altered by increasing the scope of the Marketing Boards and through widespread use of co-operative, contract farming and vertical integration. There are several reasons for these trends: in particular, the income instability of the traditional marketing system (although this has partly been mitigated by government support measures), the increased access to sources of capital and the technical advice which is frequently made available. For example, when the Milk Marketing Boards were set up in the early I 930 s the aim was clearly to handle supplies and negotiate prices from a strong position. But post-war the Boards have broadened their activities and now provide assistance to farmers with their breeding and herd management policies by operating the largest artificial insemination service in the world, herd health monitoring schemes and veterinary research. Moreover, the Boards in conjunction with the trade have developed markets for milk and milk products through sales campaigns and publicity. 
As opposed to Marketing Boards which are statutory bodies, the post-war period has witnessed a growth of farmer-controlled co-operatives which operate on a voluntary basis. There is a clear distinction between the large multi-purpose cooperatives (some of which have been set up since the First World War) and the smaller highly specific groups which have been formed over the past ten to fifteen years. The former sell to and buy from farmers in much the same way as agricultural merchants do; the latter have more usually come into being to exploit potential markets arising from the development of new production techniques or new channels of distribution. For example, co-operatives have been particularly noticeable in the production and marketing of vegetables where the use of expensive, specialized machinery or the development of new crops are obvious cases for co-operative ventures to share facilities and perhaps the services of skilled workers.

The above trends have been given further impetus by the reluctance of food manufacturers to negotiate separate contracts with thousands of small firms and the realization by farmers that they faced an increasingly highly organized food industry. Two particular changes in the food market have caused this pressure. First, the newer types of food processing systems have significant economies of scale and give rise to the desire on the part of manufacturers to keep their productive capacity as fully utilized as possible. Secondly, over the past 20 years there has been a considerable growth in the proportion of the retail food trade done by supermarkets and other types of multiple stores. In order to minimize their costs they too require quantities of highly uniform produce, appropriately packed and delivered at the right time.

However, the incidence of such developments should not be over-emphasized in explaining the tendency towards larger and more specialized farms because cooperatives, contract farming and vertical integration have not been a noticeable feature for the major crops and livestock.

\section{Conclusion}

The main conclusion to be drawn from the enviable performance of British agriculture since the war is that it has been achieved by a restructuring of the methods of production. It is interesting that successive governments have repeatedly urged British industry to restructure. Agriculture is a perfect example of what can be accomplished when those responsible for the organization of an industry are farsighted enough to adapt and discard traditional techniques and methods by taking full advantage of the advances in science and technology. Perhaps British industry has a lot to learn from agriculture.

The structural changes that have taken place within agriculture over the last $3 \circ$ years have resulted in production being increasingly transformed into more specialist units while the output of cereals, livestock, milk, pigs and eggs has more than doubled. Typical of this structural change is the rise of intensive livestock production. I have already noted the dairy sector's improved output but the trend has been even more pronounced in the production of pigs, poultry and eggs. In 
these enterprises, larger production units using relatively small areas of land and highly intensive methods go some way towards explaining why total agricultural output has risen markedly over the period while the numbers of those engaged in the industry have declined by more than a half and the area of agricultural land has diminished. However, higher yields of cereals, sugar beet and potatoes, aided by increased mechanization, together with a greater output from grassland as a result of higher stocking rates, greater use of fertilizers and general improvements in the land by means of drainage, improved grass varieties etc. have contributed most to the industry's performance over the period.

Finally, these development within the industry have inevitably brought about changes in the farmer's function. The average farmer is now far more dependent upon the manufactures of fertilizers, chemical sprays and feedingstuffs than his counterpart 30 years ago. On the marketing side, farmers have devolved a great deal of responsibility on to specialist agencies so that now they can concentrate far more on the business of growing food. Since 1945, increased education and communication have served to raise the technical and managerial competence of farmers in general. It is perhaps all too easily forgotten that the scientific and technological advances outlined above depend ultimately on the quality of the individual farmer if they are to be implemented to the nation's advantage. 